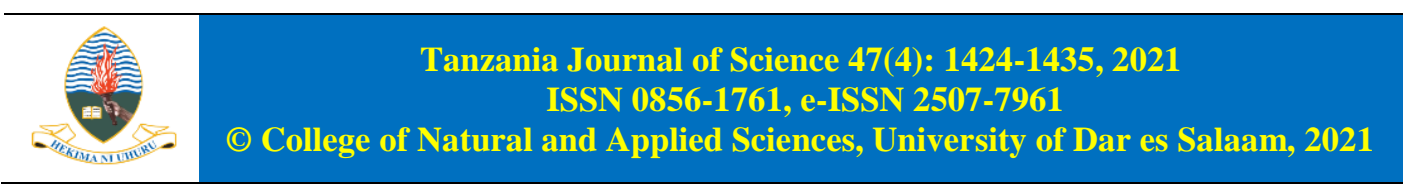

\title{
Vulnerability and Responses of Smallholder Farmers to Climate Change Effects in Semiarid Areas of Bahi and Kongwa Districts, Tanzania
}

\author{
Helena Elias Myeya \\ Department of Geography and Economics, Mkwawa University College of Education, University \\ of Dar es Salaam, P. O. Box 2512, Iringa, Tanzania. \\ Correspondence E-mail: myeyahelena@yahoo.com \\ Received 21 Jun 2021, Revised 24 Sep 2021, Accepted 29 Sep 2021, Published Oct 2021 \\ DOI: https://dx.doi.org/10.4314/tjs.v47i4.8
}

\begin{abstract}
This study examined the vulnerability and responses of smallholder farmers to climate change effects in Semiarid Areas of Bahi and Kongwa Districts. A total of 366 household heads were involved in this study. The study employed questionnaire, interviews and documentary review as data collection techniques. Archival data for temperature, rainfall and crop yields were collected for trend analysis. Descriptive and inferential statistics were used to analyse quantitative data, content analysis was employed to analyse qualitative data. Simple linear trend analysis and Mann Kendall were used to establish trends. The findings indicate that smallholder farmers in the study area have noted reduced rainfall, increased temperature and reduced production as indicators of climate change. Results from archival data indicate insignificant decline of rainfall, significant increase of temperature and insignificant decline of crop yields at 5\% significance level. As a response to these changes, smallholder farmers reported to use improved crop varieties, change planting dates, use intercropping, out-migrating and change land use practices. Several challenges were reported to hinder effective adaptation including inadequate capital, limited soft loans, limited weather information and deficient extension services. It is concluded that the climate is changing in the study area calling for strengthening farmers' adaptive capacity.
\end{abstract}

Keywords: Adaptive strategies, climate change effects, challenges, semiarid area, Tanzania.

\section{Introduction}

Reduced rainfall and increased temperature have been reported as major causes for reduced cereal crop yields worldwide, sub-Saharan Africa being mostly vulnerable (Swai et al. 2020, Msongaleli et al. 2014). Barron and Okwach (2005) asserted that cereal grains particularly maize yields in semi-arid areas of Sub-Saharan Africa (SSA) are declining to almost half of the potential values of which is linked to recurrent droughts, land degradation, population growth, low use of improved tools and poor agricultural policies.

Like other developing countries in SSA, Tanzania is also experiencing changes in climate posing challenges to food security, health and to the economy (Swai et al. 2020, Komba and Muchapondwa 2018). Extreme climatic related events in Tanzania, namely floods and droughts have posed challenges to human, livestock and the environment (Kangalawe and Lyimo 2013). The country has experienced reduced crop yields and production attributed by increased temperature and reduced rainfall (Swai et al. 2020, Msongaleli et al. 2014).

Semiarid areas of Tanzania are reported to be more vulnerable to the changing climate than other parts of the country (Myeya 2021, Sewando et al. 2016, Mutabazi et al. 2015). 1424 
Individuals and communities are reported to be differently affected by the changing climate (Kabote 2018, Komba and Muchapondwa 2018). Poor people are more vulnerable to the changing climate than wealthier people due to low adaptive capacity (IPCC 2014). Literature further indicate that women, elders, children and sick people are more exposed to climate change effects than other groups due to low adaptive capacity (Kabote 2018).

Climate change effects in Tanzania have forced smallholder farmers to practice various measures in order to reduce crop failure (Swai et al. 2020). However, it is reported that those coping strategies are limited for viable adaptation to climate change effects due to high poverty levels, poor technology use and lack of viable information on appropriate measures to be taken (Komba and Muchapondwa 2018).

Even though various studies (Komba and Muchapondwa 2018, Westengen and Brysting 2014, Balama et al. 2013) have been conducted in various places of Tanzania to investigate the effects of climate change on agriculture in semiarid areas of Tanzania, a comprehensive study that captures both perceptions of smallholder farmers and empirical evidence of the changing climate is missing. This paper investigated the indicators of climate change based on smallholder farmers' perceptions and the empirical data of climate variables (temperature and rainfall), adaptive strategies employed by smallholder farmers in reducing the magnitudes of climate change effects and challenges facing smallholder farmers in implementing viable adaptation strategies in Bahi and Kongwa Districts of Dodoma region. The results from the present research contributes to the existing body of knowledge on the analysis of temperature, rainfall and crop yields based on smallholder farmers' perceptions and empirical data thus, being useful for future climate projections. The research results might also be useful for policy formulation on appropriate ways of adaptation to the changing climate.

\section{Materials and Methods \\ Description of the study area}

This study was conducted in Bahi and Kongwa districts among the seven districts found in Dodoma region (Figure 1). Bahi is located in the western part of Dodoma extending between latitude $5^{\circ} 59^{\prime}$ South and between longitude $35^{\circ} 19^{\prime}$ East. The district occupies about $6,100 \mathrm{~km}^{2}$ and administratively it is divided into 4 divisions, 21 wards and 56 villages (BDC 2011). Conversely, Kongwa is located between latitude $6^{\circ} 12^{\prime}$ South and longitude $36^{\circ} 25^{\prime}$ East. The land area of the district is $4041 \mathrm{~km}^{2}$ divided into 3 divisions, 14 wards and 74 registered villages (KDC 2011).

\section{Rationale for selecting the study area}

The selected area is characterised by semiarid conditions, thus being more vulnerable to climate change effects than other parts of the country (Shemsanga 2010). The study area was also chosen because it has the highest number of crops growing households in Tanzania (URT 2011). This implies that a large number of households depend on agriculture, the mostly vulnerable sector to climate change. Even though the region had highest planted area per household, it was reported to have the lowest maize yields (1.02 Mt/ha) in the country (URT 2011) calling for the need to conduct a study to examine the vulnerability of smallholder farmers to the effect of climate change, their response to those changes and challenges encountered for effective adaptation.

\section{Study design and sampling techniques}

This study employed a cross-sectional design under a mixed method research approach. Concurrent mixed research approach was applied in this particular study for triangulation and complementarities purposes (Creswell 2013). The approach has been useful in this study for understanding complex issues of climate change that could not be well understood by either quantitative or qualitative alone. Both purposive and random sampling techniques were employed. Purposive sampling 
Myeya - Vulnerability and responses of smallholder farmers to climate change effects ...

was used in the selection of the study area Bahi and Kongwa districts of Dodoma region because of being more prone to the changing climate effects.

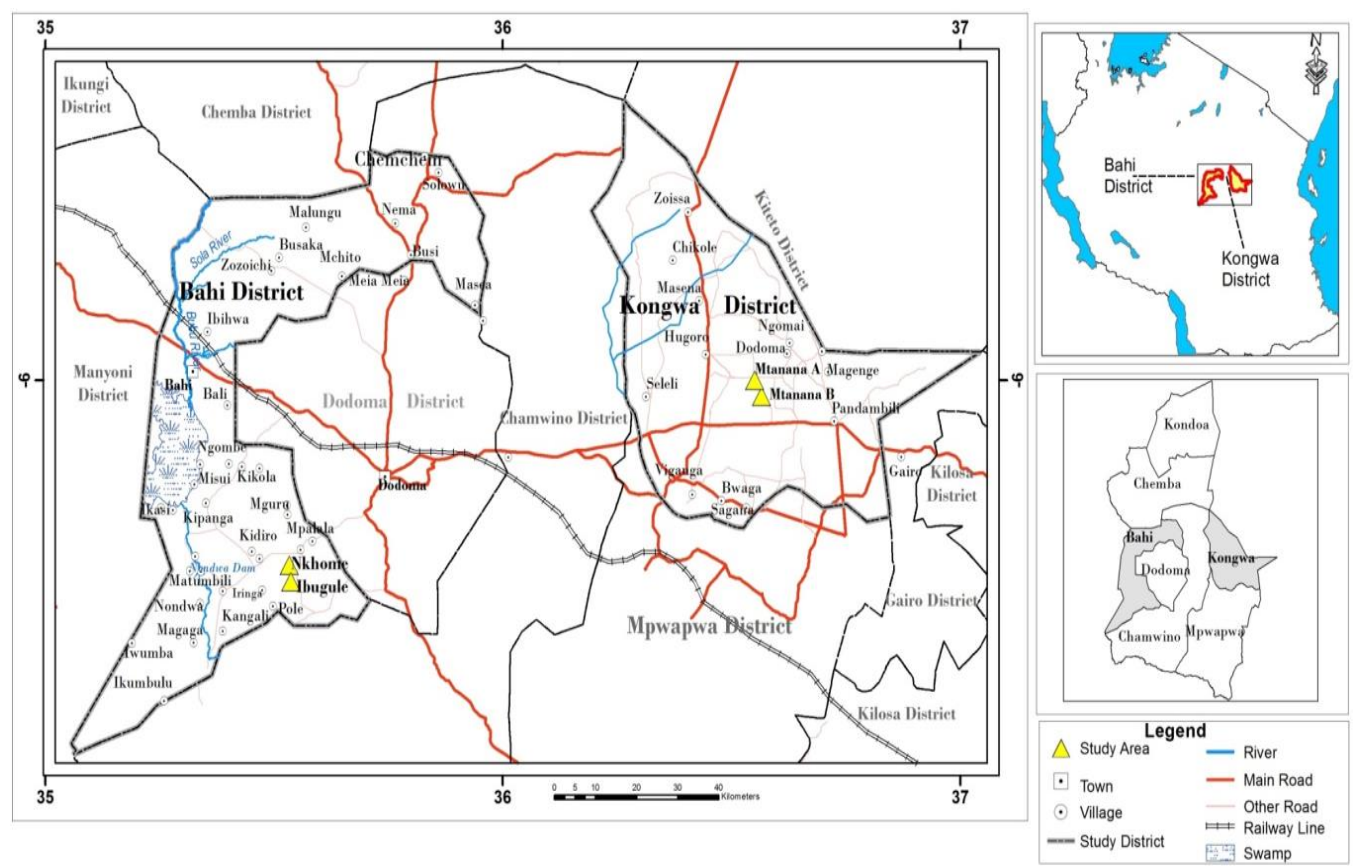

Figure 1: Map showing the study area.

\section{Sampling unit and size}

The sampling unit for this study was household heads. The heads of households were chosen because they were the decision makers at household level, thus in practice were thought to be more knowledgeable on climate change issues. A total of 366 households were technically selected from 4312 households by using a formula proposed by Yamane (1967). The formula which is based on $95 \%$ confidence level and $\mathrm{P}=0.05$ reads as:

$$
\mathrm{n}=\frac{N}{1+N(e)^{2}}
$$

where $\mathrm{n}$ is the sample size to be calculated, $\mathrm{N}$ is total population of the study (households) and $\mathrm{e}$ is the level of precision measured by probability scale of $5 \%$ level of significance. The total numbers of households were inserted in the formula as shown here under;

$$
\mathrm{n}=\frac{4312}{1+4312(0.05)^{2}}=366 \text {. }
$$

Thereafter, 366 household heads were randomly selected from four villages (2 from each district) for representation. Additionally, key informants, particularly agricultural officers, village leaders and elders were purposively selected and involved in Focus Group Discussions (FGD) and in-depth interviews due to their potentiality to the research theme. A total of 36 participants were involved in FGD and in-depth interviews.

\section{Data collection and analysis techniques}

The current study employed questionnaire survey, interviews and literature review as data collection techniques. Both closed and open ended questionnaires were administrated to smallholder farmers to capture issues related with climate change evidences, adaptive measures employed and challenges 
encountered to adapt effectively. In-depth interviews and FGD were used to complete and control for the quality of information collected by household questionnaire survey. Moreover, climatic data from Tanzania Meteorological Agency (TMA) was collected for three stations (Bahi, Dodoma and Mpwapwa) located in three districts of Dodoma region for wider representation of the study area. Additionally, data on crop yields for maize, sorghum and bulrush millet for the entire region were gathered from the Ministry of Agriculture, Food Security and Cooperative (MAFC) offices and the National Bureau of Statistics (NBS) for wider coverage.

\section{Data analysis techniques}

Both quantitative and qualitative analysis techniques were employed in analysing the research findings. Data obtained through questionnaire surveys were coded and analysed by using Statistical Package for Social Sciences (SPSS) and Microsoft Excel software to generate descriptive statistics. Qualitative data collected through interviews and FGDs were coded and arranged according to research themes through content analysis.

Before establishing trends, data for temperature, rainfall and crop yields were subjected to test for unit root problem. Augmented Dickey-Fuller (ADF) test was undertaken to test for unit root problem as applied by Blanc (2012) and Amikuzino and Donkoh (2012). The ADF test showed that there was no unit root problem associated with the data (Blanc 2012). Thereafter, simple linear trend analysis and Mann Kendall test were applied to establish and test for trends. The Mann Kendall test helps to show how strong the trend of the variables is either increasing or decreasing (Karmeshu 2012).

\section{Results and Discussion}

\section{Demographic characteristics of respondents}

Climate change adaptation measures vary based on age, gender, income and education variations (Kabote 2018). Four demographic characteristics (Table 1) of the population under study were examined to determine the status of the population under study. Results presented in Table 1 show that, majority of the respondents $(53.9 \%)$ were under two age groups (30-39 and 40-49 years). This age group is energetic, thus being able to offer labour power in farming activities effectively. Moreover, the gender composition of the population understudy comprised of $65 \%$ males and $35 \%$ females. According to the IPCC (2014), gender roles and gender relations are very crucial in climate change adaptation as they shape vulnerability and people's capacity to adapt to the changing climate.

Table 1: Demographic characteristics of household heads

\begin{tabular}{ll}
\hline $\begin{array}{l}\text { Demographic } \\
\text { characteristics }\end{array}$ & $\begin{array}{l}\text { Percentage } \\
(\mathrm{n}=366)\end{array}$ \\
\hline Age & 10.3 \\
$20-29$ & 27.1 \\
$30-39$ & 26.8 \\
$40-49$ & 14.5 \\
$50-59$ & 15.1 \\
$60-69$ & 6.2 \\
$>70$ & \\
\hline Gender & 65 \\
Male & 35 \\
Female & \\
Education & 15 \\
No formal education & 74 \\
Primary education & 10 \\
Secondary education & 01 \\
Post-secondary & \\
education & \\
\hline Marital status & 76 \\
Married & 10 \\
Single & 08 \\
Widowed & 06 \\
Divorced & \\
\hline
\end{tabular}

Apart from gender composition, the findings on education levels indicated that, majorities $(74 \%)$ of the smallholder farmers in the study area had primary school level education, $15 \%$ had no formal education, $10 \%$ had secondary education and the remaining 
Myeya - Vulnerability and responses of smallholder farmers to climate change effects ...

$1 \%$ had attained post-secondary school education level. Education levels determine smallholder farmers' ability to acquire and use knowledge and skills on climate change adaptation.

Furthermore, the findings on marital status of the smallholder farmers surveyed indicated that the majorities $(76 \%)$ of the population were married, $10 \%$ were single, $8 \%$ were widowed and $6 \%$ were divorced. The percentage of married group is higher as compared to other groups due to cultural trait where being married is a symbol of respect.

\section{Perceived and empirical evidence of climate} change

Perceived evidences on the changing climate

The findings from this study in Table 2 indicate rainfall decline to be the major indicator of the changing climate in Bahi and Kongwa Districts as pointed out by $87.7 \%$ of the respondents. Decreased rainfall was explained based on rainfall duration, intensity and intervals. During the interviews, smallholder farmers emphasized on the increased intensity of rainfall decline and temperature increase as compared to the past 15 to 30 years. Temperature increase and rainfall decline were linked to frequent crop failure and drought incidences as it was reported by one participant here under; "When we compare the current temperature feeling and rainfall amount with that of the past 15 to 30 years, one can agree with me that temperature has increased and rainfall has decreased. Drought incidences have increased and frequent crop failures have manifested in our area". Male, 65 years old from Mtatana A village, Kongwa district.

There have been similar results by other researchers in Tanzania on rainfall decline based on small holder farmers' perceptions notably Swai et al. (2020), Westengen and Brysting (2014) as well as Lyimo and Kangalawe (2010) who also reported perceived change in rainfall for different agro-ecological zones of Tanzania. Moreover, reduced crop yield was noted to be the second indicator mostly pointed by $85.8 \%$ of the respondents. Respondents linked reduced rainfall amount to have a greater effect on cereal crop yields. Smallholder farmers reported that nowadays the amount of rainfall received is not enough for crops to survive well as it used to be in the past 15-30 years. Frequent crop failures were also reported to manifest nowadays than previous years. This kind of observation resembles to the research findings by Kangalawe and Lyimo (2013) who linked erratic rainfall and recurrent droughts with reduced cereal crop yields.

Table 2: Perceived evidences of the changing climate

\begin{tabular}{llll}
\hline Indicators & $\begin{array}{l}\text { Bahi }(\mathrm{n}=148) \\
(\%)\end{array}$ & $\begin{array}{l}\text { Kongwa }(\mathrm{n}=218) \\
(\%)\end{array}$ & $\begin{array}{l}\text { Total }(\mathrm{n}=366) \\
(\%)\end{array}$ \\
\hline Decreased rainfall amounts & 86.2 & 89.3 & 87.7 \\
Decreased crop yields & 87.5 & 84.2 & 85.8 \\
Depletion of water sources & 86.1 & 81.0 & 83.5 \\
Unpredictable climate & 89.4 & 76.3 & 82.8 \\
Increased temperature & 60.2 & 74.5 & 67.3 \\
Changes of seasons & 43.0 & 28.2 & 34.1 \\
Increased drought incidences & 32.9 & 33.7 & 33.3 \\
New plants and crop diseases & 25.0 & 24.4 & 24.7 \\
\hline
\end{tabular}

NB: Analysis based on multiple responses hence column tallies exceed 100\%. 
Depletion of water sources was also among the indicators of the changing climate in Bahi and Kongwa District as pointed out by $83.5 \%$ of the surveyed population. Respondents reported that seasonal rivers, wells and dams that acted as their major sources of water for domestic and livestock purposes were no longer useful. Respondents further argued that, for the past 15 to 30 years, these sources retained water for 5 up to 6 months and some were useful till the next rainfall season. Unfortunately, nowadays water sources tend to dry up for 2 to 3 months since the rainfall cessation. The current results concur with what is reported by Kangalawe and Lyimo (2013) in semiarid areas of Tanzania.

Respondents further reported on unpredictable rainfall to be another indicator of the changing climate in Bahi and Kongwa District as pointed out by $82.8 \%$ of the surveyed population. Smallholder farmers emphasized that nowadays rainfall is unpredictable especially on rainfall onset and cessation. The reported study results on perceived indicators of the changing climate resemble to the research findings noted by Sewando et al. (2016) as well as by Kangalawe and Lyimo (2013) who also reported on unpredictable rainfall on their study areas.

\section{Empirical evidences on the changing climate Temperature patterns and trends \\ The results on temperature analysis over the} past 53 years (1961 to 2013) presented in Figure 2 indicate increased values for both the mean annual minimum and maximum temperatures. The fitted linear trends in the minimum temperature (Tmin) and maximum temperature $(\mathrm{Tmax})$ are statistically significant at the $5 \%$ significance level $(\mathrm{p}=0.000, \mathrm{p}=$ 0.001 , respectively). Based on these results, it is noted that over the past 53 years (1961 to 2013) minimum temperature in Dodoma Region has increased rapidly than the maximum temperature.

Moreover, the mean temperature of the study area for the past 53 years (1961-2013) indicates decreasing trend. The decline of the mean with a slope of $0.0091^{\circ} \mathrm{C}^{-} 1$ implies a decrease by $8.8 \%$ of variance from 1961 to 2013. A negative value implies a lower increase in the maximum temperature as compared to the minimum temperature. This is associated with the increase of hot days and nights as compared to cold days and nights. These findings are in line with what was reported by Latha et al. (2012) in India, Malik et al. (2012) in Pakistan and Sarr (2012) in Nigeria who observed increased temperature in their study areas.

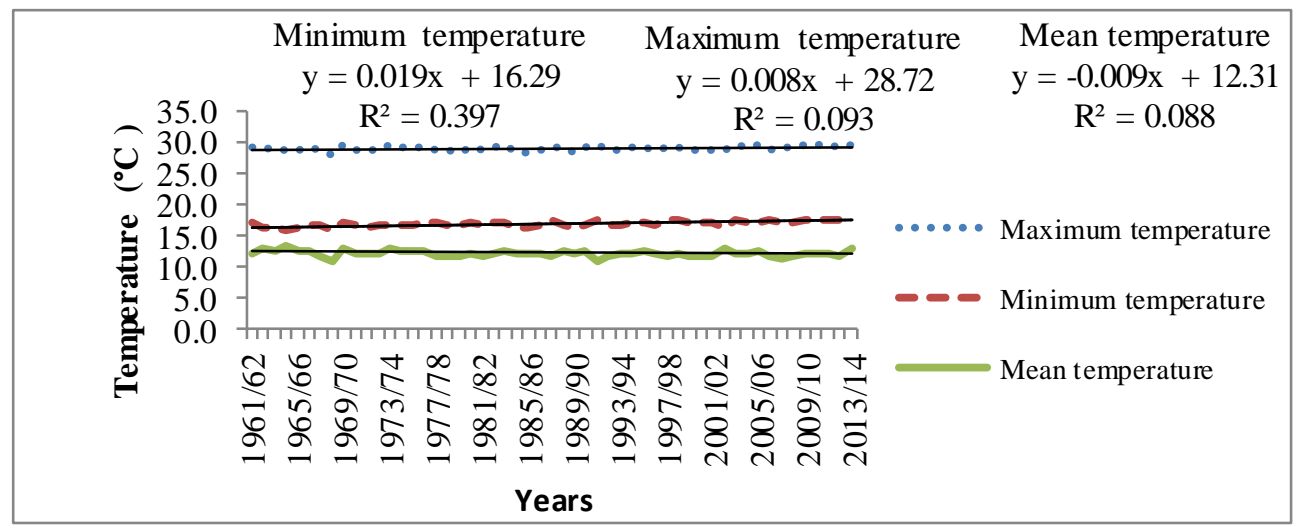

Figure 2: Minimum, maximum and diurnal temperature range covering 1961 to 2013.

Source: Computation based on TMA and WMO Data. 
Myeya - Vulnerability and responses of smallholder farmers to climate change effects ...

\section{Rainfall patterns and trends}

The results on rainfall analysis in Figure 3 indicate insignificant decreasing trends $(\mathrm{p}=$ $0.532, \mathrm{p}=0.473)$ at $5 \%$ significance level for Bahi and Mpwapwa stations, respectively. Conversely, rainfall analysis for Dodoma station indicated slightly increasing trends which is statistically insignificant $(\mathrm{p}=0.629)$ at $5 \%$ significance level.

Apart from increased trends for rainfall at Dodoma station, year to year variability was noted in all stations where some years received higher rainfall and other low rainfall of which all have implications on crop production. A good example of years with high rainfall recorded for all stations are 1967, 1982, 1989, 1997, 2004 and 2007. Conversely, 1964, 1969, 1974, 1976, 1984, 1992, 2005, 2010 and 2013 were recorded as years with low rainfall below the mean $(580 \mathrm{~mm})$ throughout the stations.
The research findings on rainfall decrease and slightly increase tally with what is reported by Myeya (2021) in Tanzania, Abaje and Oladipo (2019) in Nigeria, and Mkonda and He (2018) in Tanzania who also noted declining and increasing rainfall trends in their study areas.

\section{Cereal crop yield patterns and trends}

The research results on crop yield analysis for maize, sorghum and bulrush millet presented in Figure 4 covering 1981 to 2011 indicate a decreasing trend in all the three crops. The fitted linear trends are statistically insignificant at the $5 \%$ level of significance $(p$ $=0.202, \mathrm{p}=0.172, \mathrm{p}=0.100)$. These findings concur with what is reported by URT (2011), Rowhani et al. (2011) and Meena et al. (2008) who observed declining cereal crop yields in Tanzania.

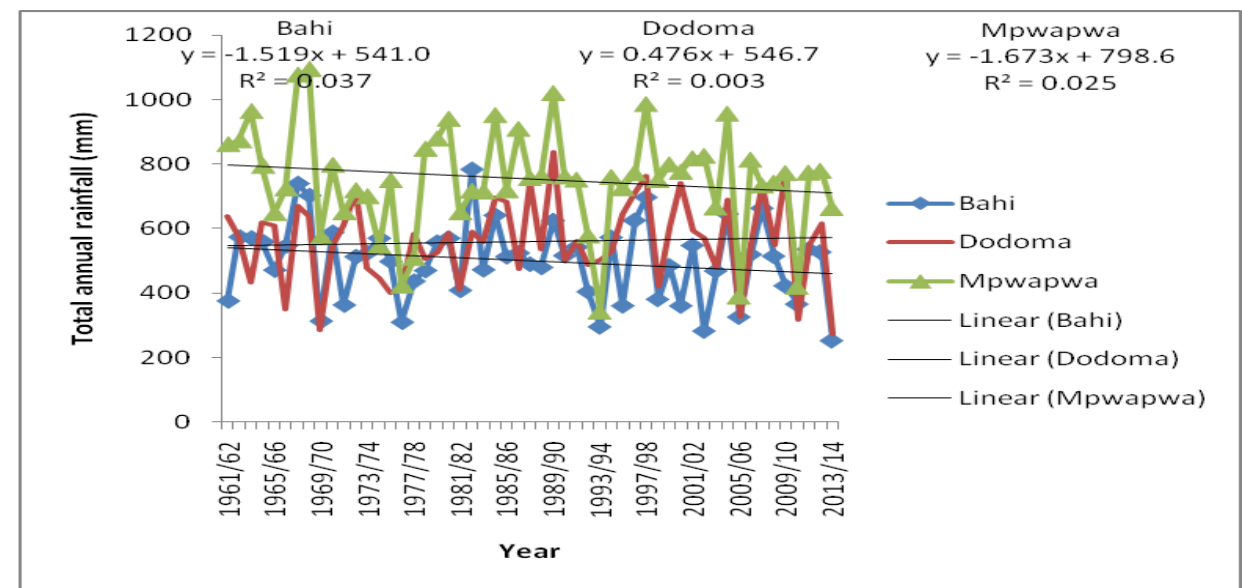

Figure 3: Mean annual rainfall covering 1961 to 2013.

Source: Computation based on TMA and WMO Data. 
Tanz. J. Sci. Vol. 47(4) 2021

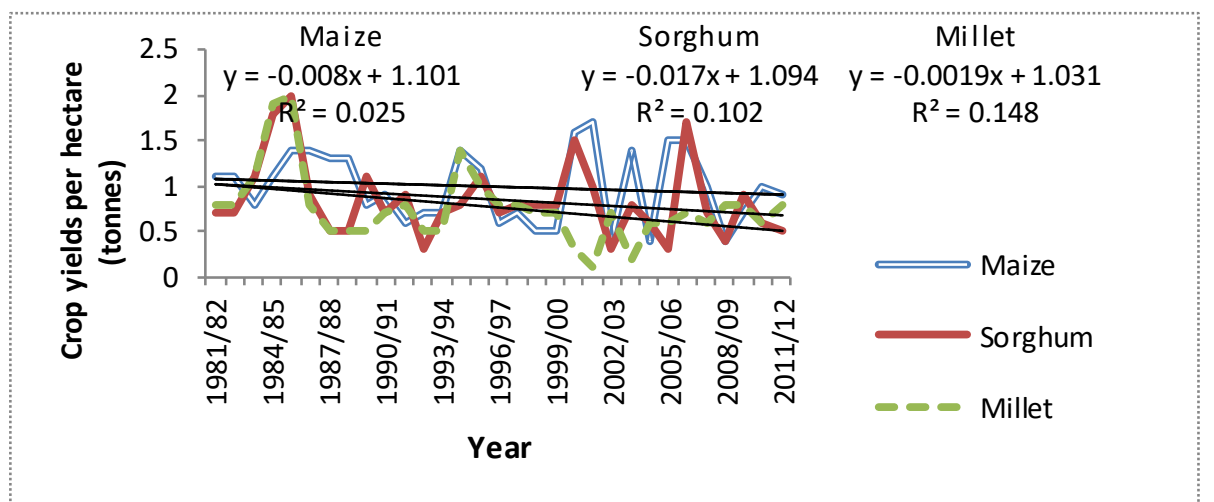

Figure 4: Mean cereal crop yields covering 1981 to 2011. Source: NBS, MAFC. (2013).

\section{Climate change adaptive strategies}

As a response to declining crop yields caused by rainfall and temperature variations, smallholder farmers in the study area have employed various strategies. The study results in Figure 5 indicate various measures including use of improved seeds, change of planting dates, use of intercropping, increase farm size, out migrating to distant places and change of land use practices. Among these strategies, use of improved seeds was reported by large number of respondents $(40.7 \%)$ and change of land use practice was reported by minority $(2.5 \%)$. Smallholder farmers reported to use improved seeds which were both drought resistant and also those which take short time to mature.

The current results are in line with what was reported by Swai et al. (2020) and Msongaleli et al. (2018) in Tanzania who reported use of improved seeds as one of climate change adaptive measures in areas where rainfall is unpredictable. Moreover, Komba and Muchapondwa (2018) affirmed that the practice of changing planting dates is used as a common strategy in many places that are impacted by increased rainfall variability.

Furthermore, Lema and Majule (2009) asserted intercropping to be among the strategies employed in semiarid areas of Tanzania to maximize yields from the little available water. Through intercropping it was reported to find different crops being grown in one piece of land aiming at reducing crop failure risk. On the other hand, Malley et al. (2009) insisted that low land productivity in Tanzania has forced farmers in semiarid areas to compensate the low production by extending their cultivation or by changing the land uses. All these strategies were noted to be employed in the study area. The mentioned strategies were reported by smallholder farmers to be used interchangeably as no one is perfect than the other.

\section{Influence of demographic characteristics on} climate change adaptive strategies

The research findings in Table 1 indicate demographic characteristics of the surveyed population, while results in Figure 5 show adaptive strategies employed by smallholder farmers in the study area. The two were correlated to see the influence of demographic characteristics on adaptive strategies. The study results shown in Table 3 indicate significant correlation between age and adaptation strategies (Chi-square $=80.977, \mathrm{df}$ $=18, \mathrm{p}=0.000)$ at $5 \%$ significance level. These results imply that age had a greater influence on adaptation options. It was noted that there were variations on implementation of adaptive measures between aged and young smallholder farmers. It was revealed that aged people were in a position to adapt to the changing climate better than young because they were in a position to own livestock and 
Myeya - Vulnerability and responses of smallholder farmers to climate change effects ...

other asserts which are very important in adaptive measures. These results concur with what was reported by Atinkut and Mebrat (2016) in Ethiopia who noted increasing age to have impacts on implementing climate adaptation strategies.

Not only age was positively correlated with adaptive measures, gender also was seen to have significant influence on adaptation strategies (Chi-square $=51.977$, df $=6, \mathrm{p}=$ $0.000)$. Women were greatly affected by the changing climate than men due to limited access and control over resources which greatly affected them to adapt effectively. These results concur with the research findings by Mabe et al. (2014) in Northern Ghana who reported positive influence of gender on adaptation strategies.

Furthermore, the study results showed also positive correlation between education and adaptive measures (Chi-square $=58.355, \mathrm{df}=$ $18, \mathrm{p}=0.000)$ at $5 \%$ significant level. These results implied that education levels had greater influence on adaptation options where those with higher education levels were in a good position to implement adaptation strategies well as compared to those with low education levels. These findings resemble to what was reported by Kinuthia et al. (2018) in Kenya who observed education levels to have significant influence on the choice of climate change adaptive strategies. While age, gender and education have shown positive effects on adaptive strategies, marital status indicated insignificant correlation with climate change adaptation strategies (Chi-square $=16.301$, df $=18, \mathrm{p}=0.572)$. This implies that no difference was noted on the influence of marital status on adaptive measures. These results tally with the findings of Odhiambo et al. (2019) who reported that respondents' marital status was found not to influence climate change adaptation by smallholder farmers in Kenya, whether individually or jointly.

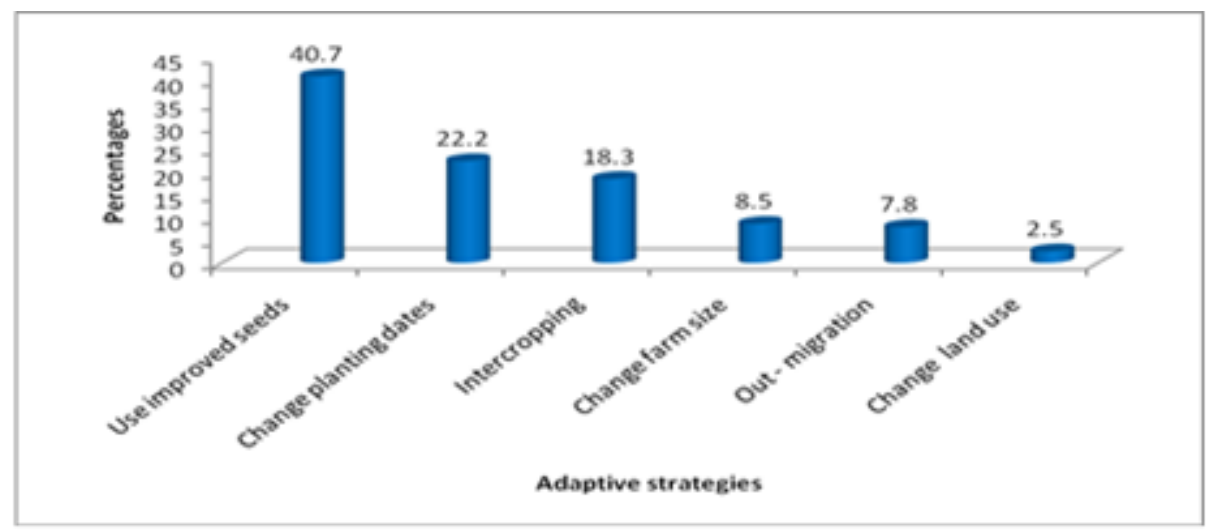

Figure 5: Smallholder farmers' adaptation strategies to the changing climate.

Table 3: Influence of demographic characteristics on adaptation strategies

\begin{tabular}{lllc}
\hline Variable & Value & Df & Asymp. Sig. (2-sided) \\
\hline Age & $80.977^{\mathrm{a}}$ & 18 & $0.000^{*}$ \\
Gender & $51.728^{\mathrm{a}}$ & 06 & $0.000^{*}$ \\
Education & $58.355^{\mathrm{a}}$ & 18 & $0.000^{*}$ \\
Marital status & $16.301^{\mathrm{a}}$ & 18 & 0.572 \\
\hline
\end{tabular}

* Significant at $0.05, \mathrm{P}<0.05$ or $=0.05$ 


\section{Challenges in adapting to the changing climate}

Though smallholder farmers in the study area have implemented various strategies in adapting to adverse effects of the changing climate, they have encountered various challenges which hinder them to adapt effectively. Results from the surveyed population (Table 4) showed that, majorities $(84.4 \%)$ of the respondents reported inadequate capital to be their major challenge in adapting to the changing climate. Respondents argued that improved production needs capital for buying improved seeds and equipment, but majority of the smallholder farmers reported to be unable to acquire the mentioned inputs because of low income levels.

Farming in the study area was seen to be mostly dominated by the use of hand hoe which has low impact on improving agricultural production. Smallholder farmers in the study area reported to be unable to buy or hire improved agricultural equipment like power tillers and tractors. The use of hand hoe forced smallholder farmers to cultivate small to medium farms which are manageable but with low returns. Only the agro-pastoralist and petty traders were in a position to use the mentioned improved agricultural equipment as pointed out by one participant during the FGD;

"Use of poor agricultural inputs and equipment is among the challenges we face where majority of us depend mostly on the use of hand hoe. Few people in our community (livestock keepers) own and use ploughs and power tillers, thus adapt well to the changing climate as compared to majority of us who lacks access and ownership on these equipments..." A female respondent aged 35 years old at Mtanana $B$ village, Kongwa district".

Limited soft loans (both cash and kind) were reported by $71.1 \%$ of respondents. Smallholder farmers reported not to have access to loans that could have solved the problem of lacking capital and low use of improved inputs and equipment. Respondents further reported that access to soft loans was very low among smallholder farmers. Not only that but also access to agricultural equipment such as power tillers and ploughs was selective as only livestock keepers were eligible as they were in a position to pay back the costs of those equipment in installments.

Low price of agricultural products was seen to be another challenge facing smallholder farmers as reported by $66.3 \%$ of the respondents. Smallholder farmers reported to produce both food and cash crops. They further argued that they incur high production costs but lack markets to sell their products in times of good harvests. Lack of reliable markets forces them to sell their products to local traders who buy at low prices which is a burden to them.

Table 4: Challenges in adapting to climate change effects

\begin{tabular}{llll}
\hline Challenges & $\begin{array}{l}\text { Bahi }(\mathrm{n}=148) \\
(\%)\end{array}$ & $\begin{array}{l}\text { Kongwa }(\mathrm{n}=218) \\
(\%)\end{array}$ & $\begin{array}{l}\text { Total }(\mathrm{n}=366) \\
(\%)\end{array}$ \\
\hline Inadequate capital & 85.5 & 83.4 & 84.4 \\
High input price & 73.5 & 72.3 & 72.9 \\
Limited soft loans & 70.1 & 72.2 & 71.1 \\
Low price for crops & 62.4 & 70.3 & 66.3 \\
Limited weather information & 50.2 & 44.5 & 47.3 \\
Frequent food insecurity & 53.4 & 38.2 & 45.8 \\
Labour shortage & 32.9 & 23.3 & 28.1 \\
Deficient extension services & 20.4 & 34.4 & 27.4 \\
Poor soils & 23.2 & 18.5 & 20.9 \\
\hline
\end{tabular}

NB: Analysis based on multiple responses hence column tallies exceed $100 \%$. 
Myeya - Vulnerability and responses of smallholder farmers to climate change effects ...

Smallholder farmers reported other challenges faced in adapting to the changing climate where limited weather information was reported by $47.3 \%$, frequent food shortage was reported by $45.8 \%$, labour shortage was reported by $28.1 \%$, inadequate extension services was reported by $27.4 \%$ and poor soil was reported by $20.9 \%$. The reported research results on obstacles towards climate change adaptation are in line with what was reported by Kabote (2018) and Mutabazi et al. (2015) in Tanzania who also noted various challenges which hinder smallholder farmers to adapt effectively to the changing climate.

\section{Conclusion and Recommendations}

The research results of this study have shown temperature and rainfall to have both increasing and decreasing trends with negative effects on crop production. Though smallholder farmers have employed various adaptive strategies, declining crop yields is still reported. This calls for more interventions on awareness creation in implementing viable adaptation strategies in the study area and other places of the same nature to reduce adverse effects of climate change on crop production by strengthening smallholder farmers' adaptive capacity.

\section{Acknowledgement}

The author extends her sincere thanks to the smallholder famers in Bahi and Kongwa Districts for their support, the Tanzanian Meteorological Agency (TMA) and the National Bureau of Statistics for supplying temperature, rainfall and crop yield data used in this study.

\section{References}

Abaje I B and Oladipo EO 2019 Recent changes in the temperature and rainfall conditions over Kaduna State, Nigeria. Ghana J. Geogr. 11: 127-157.

Amikuzino J and Donkoh SA 2012 Climate variability and yields of major staple food crops in Northern Ghana. Afric. Crop Sci. J. 20: $349-360$.
Atinkut B and Mebrat A 2016 Determinants of farmers choice of adaptation to climate variability in Dera woreda, south Gondar zone, Ethiopia. Environ. System Res. 5: 2-8.

Bahi District Council (BDC) 2011 District Agricultural Development Plans (DADPs) 2011/2012-2013/2014; Prime Minister's Office: Regional administration and local government, Bahi, Dodoma.

Balama C, Augustino S, Eriksen S, Makonda F and Amanzi N 2013 Climate change adaptation strategies by local farmers in Kilombero district, Tanzania. Ethiop. $J$. Environ. Studies Manage. 6: 724-736.

Barron J and Okwach G 2005 Run-off water harvesting for dry spell mitigation in maize: results from on-farm research in semi-arid Kenya. Agric. Water Manag. 74:1-21.

Blanc E 2012 The impact of climate change on crop yields in Sub-Saharan Africa. American Journal of Climate Change 1: 1- 13.

Creswell JW 2013 Research design: Qualitative, quantitative, and mixed methods approaches: SAGE Publications, Incorporated.

Intergovernmental Panel for Climate Change (IPCC) 2014 Climate change: Impacts, Adaptation and Vulnerability; Summary for policy makers. Cambridge University Press, Cambridge United Kingdom.

Kabote SJ 2018 Farmers' vulnerability to climate change impacts in semi-arid environments in Tanzania: A Gender Perspective. In: Arid Environments and Sustainability. IntechOpen.

Kangalawe RM and Lyimo JG 2013 Climate change, adaptive strategies and rural livelihoods in semiarid Tanzania. Nat. Resour. 4: 266-278.

Karmeshu N 2012 Trend detection in annual temperature and precipitation using the Mann Kendall Test. A case study to assess climate change on selected States in the Northeastern United States, USA.

Kinuthia KJ, Inot SK and Nakhone L 2018 Factors influencing farmer's choice of crop production response strategies to climate change and variability in Narok East subcounty, Kenya. J. Nat. Resour. Dev. 8: 69-77.

Komba C and Muchapondwa E 2018 Adaptation to climate change by smallholder farmers in Tanzania. Agricultural adaptation to climate change in Africa pp. 129-168, Routledge. 
Kongwa District Council (KDC) 2011 District Agricultural Development Plans (DADPs) 2011/2012-2013/2014; Prime Minister's Office: Regional administration and local government, Bahi, Dodoma.

Latha A, Gopinath M and Bhat A 2012 Impact of climate change on rain fed Agriculture in India; A case study of Dharwad. Int. J. Environ. Sci. Dev. 3: 368-371.

Lema MA and Majule AE 2009 Impacts of climate change, variability and adaptation strategies on agriculture in semi-arid areas of Tanzania: The case of Manyoni District in Singida Region, Tanzania. Afric. J. Environ. Sci. Technol. 3: 206-218.

Lyimo JG and Kangalawe YM 2010 Vulnerability and adaptability strategies to the impacts of climate change and variability, the case of rural households in semi-arid Tanzania. J. Environ. Econ. 1: 89-97.

Mabe FN, Sienso G and Donkoh SA 2014 Determinants of choice of climate change adaptation strategies in northern Ghana, Res. Appl. Econ. 6: 75-94.

Malik KM, Mahmood A, Kazmi DH and Khan JM 2012 Impact of climate change on agriculture during winter season over Pakistan. Agric. Sci. 3: 1008-1018.

Malley ZJU, Taeb M and Matsumoto T 2009 Agricultural productivity and environmental insecurity in the Usangu plain, Tanzania: Policy implications for sustainability of agriculture. Environ. Dev. Sustain. 11: 175195.

Meena H, Lugenja M, Ntikha OA and Helmes M 2008 Analyses of technological and policy options for adaptation to consequences of climate change: Overview of Agro-Ecological Zones Adaptation: The Case of Crops and Livestock, Research Report Done by CEEST and NCAP, Tanzania.

Mkonda MY and He X 2018 Climate variability and crop yields synergies in Tanzania's semiarid agroecological zone. Ecosystem Health and Sustainability 4: 59-72.

Msongaleli B, Rwehumbiza F, Tumbo SD and Kihupi NI 2014 Sorghum yield response to changing climatic conditions in semi-arid central Tanzania: evaluating crop simulation model applicability. Agric. Sci. 5: 822-833.
Mutabazi KD, Sieber S, Maeda C and Tscherning K 2015 Assessing the determinants of poverty and vulnerability of smallholder farmers in a changing climate: the case of Morogoro region, Tanzania. Reg. Environ. Change 15: $1243-1258$

Myeya HE 2021 Recent temperature and rainfall characteristics in Dodoma Region, central Tanzania (1961-2013). Ghana J. Geogr. 13: 63-80.

Odhiambo CO, Wasike CB and Ogindo HO 2019 Effect of socio-demographic characteristics on Kenyan smallholder dairy farmers' adaptive strategies to climate change effects. Atmosphere Clim. Sci. 9: 583-599.

Rowhani P, Lobell D, Linderman $\mathrm{M}$ and Ramankutty N 2011 Climate change and crop production in Tanzania. Agric. Forest Meteol. 151: 449-460.

Sarr B 2012 Present and future climate change in the semi-arid region of West Africa: A crucial input for practical adaptation in agriculture. Atmospheric Science Letters 13(2): 108-112.

Sewando PT, Mutabazi KD and Mdoe NY, 2016 Vulnerability of agro-pastoral farmers to climate risks in northern and central Tanzania. Dev. Studies Res. 3(1): 11-24.

Shemsanga C, Omambia AN and Gu Y 2010 The cost of climate change in Tanzania: impacts and adaptations. J. Am. Sci. 6: 182-196.

Swai EY, Njau F and Farrely M 2020 Enhancing the capacity of vulnerable community to climate change: Role of quality declared seed production model in semi-arid areas of central Tanzania. In: Leal Filho W (Eds) Handbook of Climate Change Resilience. Springer, Cham.

United Republic of Tanzania (URT) 2011 Basic data: Agriculture and cooperative sector 2005/2006-2009/2010; statistics unit, planning and marketing division, Government Printer, Dar es Salaam.

Westengen OT and Brysting AK 2014 Crop adaptation to climate change in the semi-arid zone in Tanzania: the role of genetic resources and seed systems. Agriculture and Food Security 3: 1-12.

Yamane T 1967 Statistics an introductory analysis, second ed. Harper and Row, New York. 